\title{
Oxygen: Friend or foe in the COVID-19 battle
}

\author{
Kishan Chudasama ${ }^{1}$ and Esmail Sangey ${ }^{1}$ \\ ${ }^{1}$ Shree Hindu Mandal Hospital
}

October 30, 2021

\begin{abstract}
Liberal use of oxygen plays a significant role in exacerbating the long-term lung injuries associated in COVID-19. Hypoxemia and hypoxia are two different entities. Correcting hypoxemia without hypoxia tends to have disastrous effect and delays lung healing.
\end{abstract}

\section{Introduction}

Oxygen is one of the most common and inexpensive treatment components in today's world of modern medicine. It is the most essential medicinal gas available in majority of the hospitals and highly beneficial when used in appropriate amounts. However, it must be acknowledged that too much of anything tends to do more harm than good, and even oxygen therapy is no exception.

When one talks about oxygen, hypoxia and hypoxemia are two such terminologies often encountered and used interchangeably. It is of paramount importance to note that these two terminologies, though they may overlap are not synonymous. Hypoxia is a state of insufficient amount of oxygen in the tissues whereas hypoxemia is a decreased amount of oxygen content in the blood. Hypoxemia may often go unnoticed, and when homeostatic mechanisms no longer compensate, can lead to hypoxia.(1)

With the ongoing COVID-19 pandemic, oxygen utilization has been on the rise worldwide, with some countries often experiencing scarcity in such crucial times.(2) The goal of oxygen therapy in COVID-19, as with any other form of respiratory illness, is to treat hypoxia. The WHO has classified severe COVID-19 to have saturations less than $90 \%$ and thus warranting supplemental oxygen therapy.(3) In an effort to treat the hypoxia, prolonged oxygen therapy may lead to pathophysiological processes associated with increased levels of hyperoxia-induced reactive oxygen species (ROS) which may readily react with surrounding biological tissues causing protein denaturation and breaking down of nucleic acids into strands.(4) Here, we describe a case of a patient with COVID-19 treated at our hospital.

\section{Case presentation}

A 64 year old male with hypothyroidism, on a daily dose of levothyroxine $100 \mathrm{mcg}$, presented to our emergency department with the complaint of difficulty in breathing of gradual onset and progressive in nature for the past 5 days associated with chest tightness. He denied the presence of any other symptoms. He had a history of coming into contact with COVID-19 patients and a history of domestic travel within the country in the last two weeks.

The only abnormal findings on physical examination were oxygen saturations of $79 \%$ on room air and tachypnoea of 26 breaths/min. Blood pressure and heart rate on arrival were 124/71 $\mathrm{mmHg}$ and 101 beats per minute respectively. Chest auscultation revealed bilateral basal crackles anteriorly and the entirety of the posterior, superior and inferior aspects had crackles. It was noted that the patient experienced fatiguability on moderate exertion however had no difficulty in completing sentences. 
Chest X-ray (PA and lateral views) was done and revealed bilateral peripheral and central alveolar infiltrates suggestive of atypical pneumonia (Figure 1). Nasal swab PCR test for COVID-19 was positive. A series of blood investigations were performed on Day 1, 3, 5 and 7 of hospital stay (Table 1).

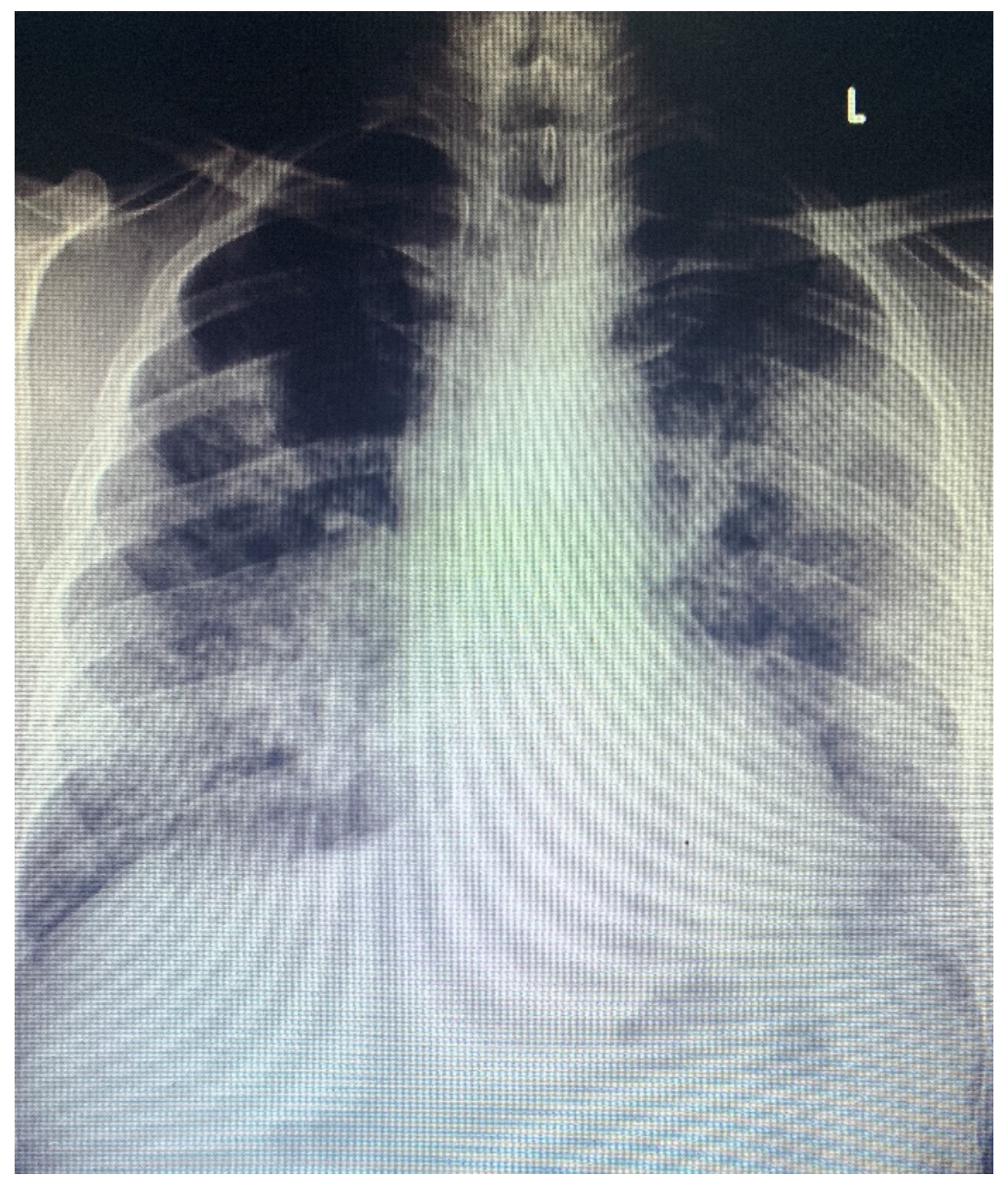




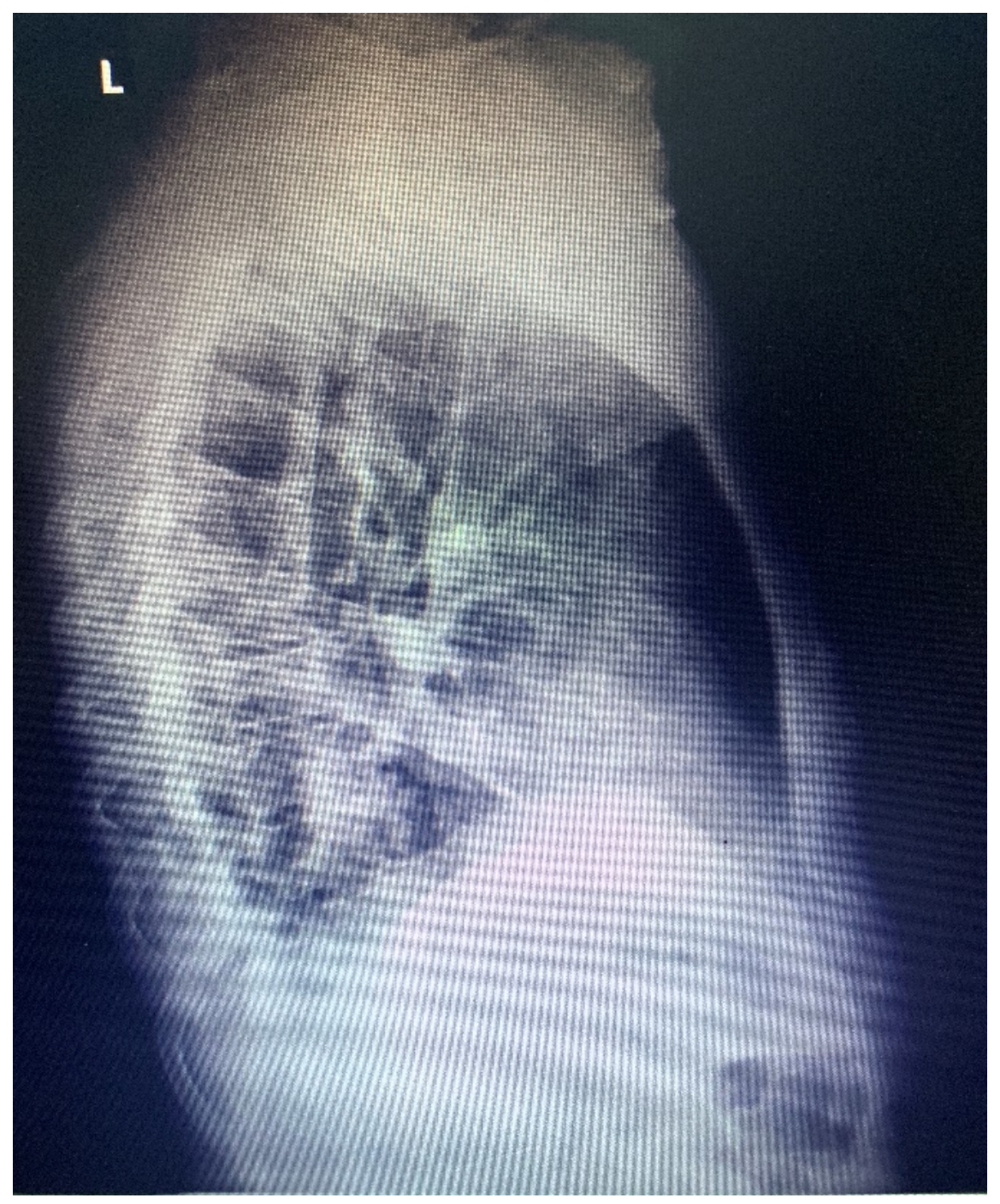

Figure 1. Bilateral peripheral and central alveolar infiltrates on chest X-ray.

Table 1: Table of results

\begin{tabular}{|c|c|c|c|c|}
\hline INVESTIGATION & DAY 1 & DAY 3 & DAY 5 & DAY 7 \\
\hline WBC (10x9/L) & 13.4 & 16.4 & 16.1 & 9.3 \\
\hline NEU $(10 \times 9 / L)$ & 11.8 & 14.2 & 12.1 & 6.2 \\
\hline LYM $(10 \times 9 / L)$ & 1.1 & 0.4 & 2.2 & 2.4 \\
\hline PLT $(10 \times 9 / L)$ & 240 & 315 & 403 & 294 \\
\hline $\mathrm{HB}(\mathrm{g} / \mathrm{dL})$ & 15.7 & 15.4 & 15.8 & 15.2 \\
\hline BUN (mmol/L) & 4.5 & 7.9 & 4.9 & 5.1 \\
\hline "PEATININE $(\mu \mu \sigma \lambda / \Lambda)$ & 117 & 182 & 98 & 102 \\
\hline FERRITINE (ng/ml) & 521 & 3000 & 2022 & 298 \\
\hline D-DIMER (mg/L) & 2.7 & - & 0.04 & 0.03 \\
\hline $\operatorname{ALBUMIN}(\mathrm{g} / \mathrm{L})$ & 36 & 42 & 30 & 34 \\
\hline $\mathrm{Na}(\mathrm{mmol} / \mathrm{L})$ & 141 & 141 & 137 & 141 \\
\hline K (mmol/L) & 3.7 & 4.6 & 3.4 & 3.6 \\
\hline
\end{tabular}




\begin{tabular}{|c|c|c|c|c|}
\hline INVESTIGATION & DAY 1 & DAY 3 & DAY 5 & DAY 7 \\
\hline $\mathrm{Cl}(\mathrm{mmol} / \mathrm{L})$ & 103 & 106 & 98 & 105 \\
\hline
\end{tabular}

It was exceptional and noteworthy that throughout his hospital stay, the patient was never supplemented with any oxygen but continued with pharmacological therapies. The patient was on intravenous Ceftriaxone $2 \mathrm{~g}$ once a day, Methylprednisolone 125mg, oral Azithromycin 500mg and Colchicine $1 \mathrm{mg}$ once a day. He was also on oral multivitamin and mineral supplements throughout his hospital stay and continued post discharge. He was initiated on a Heparin infusion of $2000 \mathrm{IU} /$ hour for a duration of 5 days, along with Warfarin $5 \mathrm{mg}$ once a day. He also received a stat dose of Tocilizumab $600 \mathrm{mg}$ on day 3 of his admission. Chest physiotherapy using a spirometer was encouraged and along with awake prone positioning 6 to 12 hourly.

From day 5 onwards, the trend of results showed an improvement in numbers and likewise clinical improvement was noted in the patient along with the subsiding of chest tightness and fatiguability. Tachypnoea subsided over time returning the patient to an almost normal respiratory rate and room air oxygen saturations showed some improvement, with the highest levels recorded being $92 \%$, constant up to the point of discharge and for isolation at home on day 8 since admission.

\section{Discussion}

Patients who presented to our hospital with COVID-19 related respiratory distress have had varying forms of oxygen supplementation ranging from those with mild distress on nasal cannulas to those with severe acute respiratory distress syndrome (ARDS) on invasive mechanical ventilation. The only variation in the treatment of this patient as opposed to others was oxygen. The patient in this case was never once supplemented with any oxygen for the entire duration of admission. The reason for withholding supplemental oxygen was the relative clinical stability of this patient despite presenting with hypoxemia. Prior to this case, we had observed several patients with similar clinical presentation who were supplemented with oxygen to meet a required high-set oxygen target. Eventually they ended up having prolonged hospital stay with an increased oxygen demand overtime. Long-term exposure to high levels of oxygen can cause lung injury in the absence of mechanical ventilation, but the combination of these two becomes more lethal leading to further lung damage.(5)

During viral respiratory illnesses, ROS are necessary for eradicating viruses, thus aiding immune cells in phagocytoses function and in signal transduction. Excessive oxygenation can cause the amount of ROS to exceed the required redox homeostasis leading to histologically progressive destruction of alveolocapillary membranes causing obstruction of capillaries forming microthrombi and air leaks via already injured alveoli into the surrounding tissues.(6) Eventually prolonged iatrogenic exposure to oxygen in combination with COVID-19 can exacerbate cell apoptosis at the alveolar epithelium level resulting into pulmonary fibrosis over an extended time period.(7)

Lung tissues are protected by overactive immune mediated Adenosine $\mathrm{A}_{2 \mathrm{~A}}$ receptor cells. These immune cells play a critical role in the down-regulation of pulmonary inflammation. Uncontrolled pulmonary inflammation occurs when continuous amount of oxygen is administered that weakens the Adenosine $\mathrm{A}_{2 \mathrm{~A}}$ receptor mediated anti-inflammatory mechanism, thereby further exacerbating lung damage.(8) A study done on a small population receiving inhaled Adenosine showed promising results in patients with COVID-19 in an attempt to therapeutically compensate for the oxygen-related loss of the endogenous adenosine receptor $\left(\mathrm{A}_{2 \mathrm{~A}} \mathrm{R}\right)$-mediated cells and reduce the lung destructing inflammatory process.(9)

Most pulmonary and non-pulmonary related studies recommend that no oxygen supplementation is required when oxygen saturation is more than $92 \%$. Oxygen supplementation should start only if oxygen saturation is less than 90\%.(10) However no consensus has yet been established on what the oxygenation target should be in hypoxemic respiratory failure patients.(11) 
A meta-analysis study published even before the COVID-19 pandemic described that hyperoxia for a duration of more than 12 to 24 hours often led to serious deleterious side-effects. It was also noted that hyperoxia of even shorter durations may be associated with increased morbidity and mortality in ICU patients.(12) The mortality rates of acutely ill adults in multiple clinical syndromes were lower in those who received conservative amount of oxygen as opposed to the liberal batch.(13)

Recent observation proposes no direct evidence of the benefit of providing supplemental oxygen therapy in the absence of hypoxia in COVID-19 patients such as in patients with low oxygen saturations who are perfectly comfortable or rather, "happy hypoxemic." It may be used to wean patients off ventilatory support but its use on patients whose lungs have adapted to hypoxemia or who do not require invasive therapy may in turn lead to adverse consequences.(2) Overcorrecting hypoxemia may improve it in the short term, but its long term effects can lead to oxygen induced ARDS and ventilator associated lung injury. This data suggests that the lungs have a better chance of recovery from COVID-19 when exposed to less oxygenation and invasive ventilation. Permissive hypoxemia was found to be feasible and had a better patient outcome when focused on oxygen content $\left(\mathrm{CaO}_{2}\right)$ rather than oxygen saturations $\left(\mathrm{SaO}_{2}\right) \cdot(14)$

Based on these oxygen studies and our observation of patients, we could postulate that in patients undergoing a cytokine storm due to COVID-19, prolonged and excessive oxygen therapy adds insult in the form of oxygen reactive species, to an already injured lung. We do not know if this is an isolated case among millions or whether depriving this patient of oxygen did indeed work to his benefit. COVID-19 pneumonia no doubt requires some form of oxygen, but the conundrum lies with those presenting with a mild form of respiratory distress, who despite having low saturations have minimal to no discomfort. COVID-19 respiratory distress presents with an unconventional pathogenesis in terms of hypoxemic patients and their progression to ARDS. Oxygen can do both, heal and harm, and in the setting of COVID-19, which is still a new evolving disease, the question isn't really about whether or not oxygen is required, but rather how much is required.

\section{Conclusion}

Condemning the use of oxygen in patients undergoing respiratory distress, be it from COVID-19 or any other illness is not the aim of this report. We are inquisitive to understand the role of oxygen in the treatment of COVID-19 and how best to titrate and use it to our benefit. Various studies have indeed been done on the beneficial and detrimental effects of oxygen but not in the context of severe ARDS or pneumonia in relation to COVID-19. It is our hope that this case will inspire the need of further research using a bigger sample size to determine how much oxygen is too much in this new disease.

\section{Conflict of interest}

None declared.

\section{Author contributions}

Kishan Chudasama gathered the data and wrote the original draft. Esmail Sangey and Kishan Chudasama involved in editing of the manuscript. Esmail Sangey involved in supervision and submission of the manuscript. All took care of the patient and have approved the final version of the manuscript.

\section{Ethical approval}

Informed and written consent was obtained from the patient to publish in this case report.

\section{Data availability statement}

The data that support the findings of this study are openly available in Authorea at https://doi.org/10.22541/au.163398431.18225231/v1

\section{References}

1. Bhutta BS, Alghoula F, Berim I. Hypoxia. In: StatPearls [Internet]. Treasure Island (FL): StatPearls Publishing; 2021 [cited 2021 Oct 6]. Available from: http://www.ncbi.nlm.nih.gov/books/NBK482316/ 
2. Goyal DK, Mansab F, Bhatti S. Room to Breathe: The Impact of Oxygen Rationing on Health Outcomes in SARS-CoV2. Front Med [Internet]. 2021 [cited 2021 Aug 3];0. Available from: https://www.frontiersin.org/articles/10.3389/fmed.2020.573037/full

3. COVID-19 Clinical management: living guidance [Internet]. [cited 2021 Oct 6]. Available from: https://www.who.int/publications-detail-redirect/WHO-2019-nCoV-clinical-2021-1

4. Mach WJ, Thimmesch AR, Pierce JT, Pierce JD. Consequences of Hyperoxia and the Toxicity of Oxygen in the Lung. Nurs Res Pract. 2011 Jun 5;2011:e260482.

5. Roan E, Wilhelm K, Bada A, Makena PS, Gorantla VK, Sinclair SE, et al. Hyperoxia alters the mechanical properties of alveolar epithelial cells. Am J Physiol - Lung Cell Mol Physiol. 2012 Jun 15;302(12):L1235-41.

6. Chernyak BV, Popova EN, Prikhodko AS, Grebenchikov OA, Zinovkina LA, Zinovkin RA. COVID-19 and Oxidative Stress. Biochem Biokhimiia. 2020;85(12):1543-53.

7. Fukumoto J, Leung J, Cox R, Czachor A, Parthasarathy PT, Lagishetty V, et al. Oxidative stress induces club cell proliferation and pulmonary fibrosis in Atp8b1 mutant mice. Aging. 2019 Jan 13;11(1):209-29.

8. Thiel M, Chouker A, Ohta A, Jackson E, Caldwell C, Smith P, et al. Oxygenation Inhibits the Physiological Tissue-Protecting Mechanism and Thereby Exacerbates Acute Inflammatory Lung Injury. PLoS Biol. 2005 Jun;3(6):e174.

9. Correale P, Caracciolo M, Bilotta F, Conte M, Cuzzola M, Falcone C, et al. Therapeutic effects of adenosine in high flow 21\% oxygen aereosol in patients with Covid19-pneumonia. PLoS ONE. 2020 Oct 8;15(10):e0239692.

10. Moss BJ, Sargsyan Z. Things We Do For No Reason: Supplemental Oxygen for Patients without Hypoxemia. J Hosp Med. 2020 Apr 1;14(4):242-4.

11. Evans L, Rhodes A, Alhazzani W, Antonelli M, Coopersmith CM, French C, et al. Surviving sepsis campaign: international guidelines for management of sepsis and septic shock 2021. Intensive Care Med [Internet]. 2021 Oct 2 [cited 2021 Oct 4]; Available from: https://doi.org/10.1007/s00134-021-06506-y

12. Hafner S, Beloncle F, Koch A, Radermacher P, Asfar P. Hyperoxia in intensive care, emergency, and peri-operative medicine: Dr. Jekyll or Mr. Hyde? A 2015 update. Ann Intensive Care. 2015 Nov 19;5(1):42.

13. Chu DK, Kim LH-Y, Young PJ, Zamiri N, Almenawer SA, Jaeschke R, et al. Mortality and morbidity in acutely ill adults treated with liberal versus conservative oxygen therapy (IOTA): a systematic review and meta-analysis. Lancet Lond Engl. 2018 Apr 28;391(10131):1693-705.

14. Voshaar T, Stais P, Köhler D, Dellweg D. Conservative management of COVID-19 associated hypoxaemia. ERJ Open Res. 2021 Mar 15;7(1):00026-2021. 

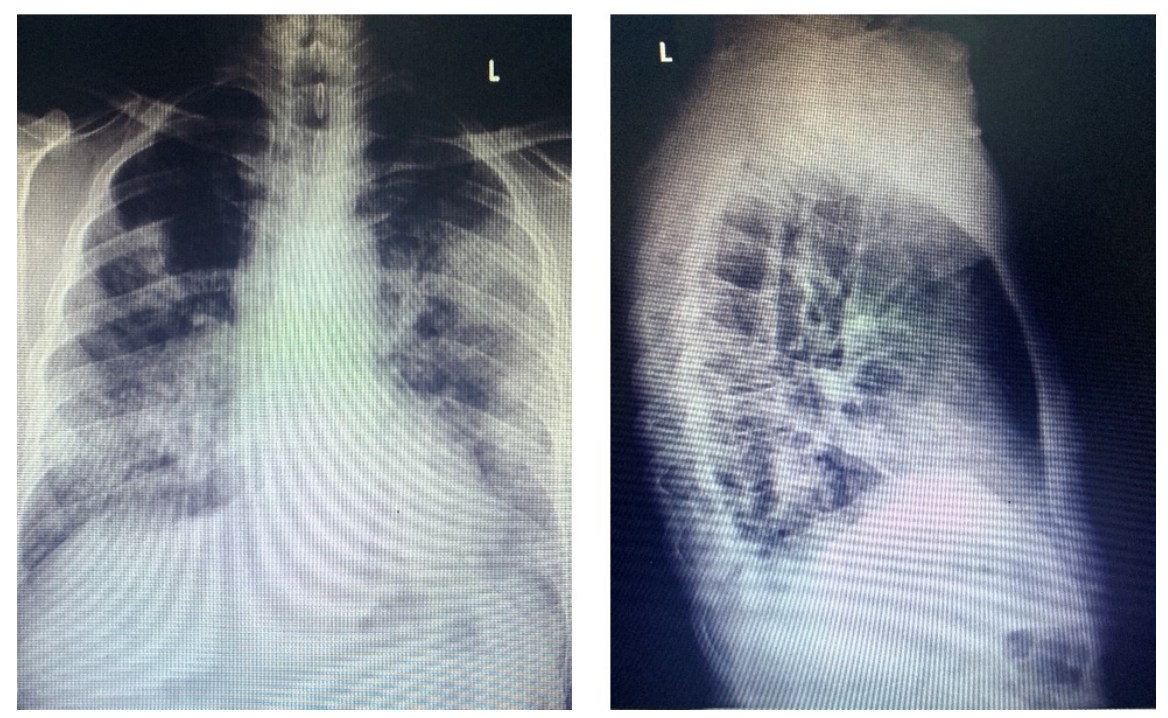

\begin{tabular}{|c|c|c|c|c|}
\hline INVESTIGATION & DAY 1 & DAY 3 & DAY 5 & DAY 7 \\
\hline WBC (10x9/L) & 13.4 & 16.4 & 16.1 & 9.3 \\
\hline NEU (10x9/L) & 11.8 & 14.2 & 12.1 & 6.2 \\
\hline LYM (10x9/L) & 1.1 & 0.4 & 2.2 & 2.4 \\
\hline PLT (10x9/L) & 240 & 315 & 403 & 294 \\
\hline HB (g/dL) & 15.7 & 15.4 & 15.8 & 15.2 \\
\hline BUN (mmol/L) & 4.5 & 7.9 & 4.9 & 5.1 \\
\hline CREATININE $(\mu \mathrm{mol} / \mathrm{L})$ & 117 & 182 & 98 & 102 \\
\hline FERRITINE (ng/ml) & 521 & 3000 & 2022 & 298 \\
\hline D-DIMER (mg/L) & 2.7 & - & 0.04 & 0.03 \\
\hline ALBUMIN (g/L) & 36 & 42 & 30 & 34 \\
\hline $\mathrm{Na}(\mathrm{mmol} / \mathrm{L})$ & 141 & 141 & 137 & 141 \\
\hline $\mathrm{K}(\mathrm{mmol} / \mathrm{L})$ & 3.7 & 4.6 & 3.4 & 3.6 \\
\hline $\mathrm{Cl}(\mathrm{mmol} / \mathrm{L})$ & 103 & 106 & 98 & 105 \\
\hline
\end{tabular}

